\title{
Understanding and Practicing Emptiness
}

\author{
William Van Gordon $^{1}$ (D) Supakyada Sapthiang ${ }^{2} \cdot$ Paul Barrows $^{1} \cdot$ Edo Shonin $^{2}$
}

Accepted: 9 December 2020 / Published online: 8 January 2021

(C) The Author(s) 2021

In terms of the evolution of Buddhist-inspired contemplative psychology, there have been three key empirical phases during the last 40 years. The first phase commenced in the early 1980s and involved exploring the construct and applications of mindfulness along with related attentional processes. This was followed at the turn of the twenty-first century by a second phase of research into Buddhist techniques concerned with socio-empathetic and ethical awareness, such as lovingkindness meditation and compassion meditation. However, during approximately the last 7 years, a third phase of contemplative psychology research has emerged, concerned with empirical investigation into the characteristics and applications of Buddhist wisdom practices.

This phasic evolution of scientific investigation is consistent with the traditional Buddhist "three trainings" (Sanskrit: trisik ksāa) principle, which classifies contemplative techniques into those primarily concerned with wisdom, ethics, or meditation. For example, in the core Buddhist teaching of the Noble Eightfold Path, the practices of (i) right view and right intention correspond to wisdom; (ii) right speech, right action, and right livelihood correspond to ethics; and (iii) right effort, right mindfulness, and right meditation correspond to meditation. In some Buddhist systems, the three trainings principle is sometimes contextualized as view (i.e., wisdom), action (i.e., ethics), and meditation.

If a path of contemplative practice is to be considered effective and complete, all three elements of the three trainings principle must be present and correctly applied. This is because in order to elicit wisdom as to the ultimate nature of phenomena and reality, meditative focus and stability are required. But to be able to meditate effectively, ethical and

William Van Gordon

w.vangordon@derby.ac.uk

1 Human Sciences Research Centre, University of Derby, Kedleston Road, Derby, Derbyshire DE22 1GB, UK

2 Awake to Wisdom Centre for Meditation and Mindfulness Research, Derby, UK socio-empathic awareness are necessary, as this helps to prevent the mind from becoming distracted, agitated, or anxious.

\section{What is Emptiness?}

The wisdom component of the three trainings principle encompasses practices and constructs that help to undermine suffering through cultivating insight into the true manner in which we and all things exist. In this regard, ancient contemplative notions such as emptiness, non-self, non-duality, nonattachment, impermanence, interdependence, and interconnectedness are particularly important. However, of all these wisdom principles, the most important is arguably emptiness.

Emptiness (Sanskrit: śünyatā) implies that although phenomena are perceptible to the human mind, they do not intrinsically exist. This is not the same as saying that they do not exist at all, but rather that they exist only in a relative manner. In other words, a key principle of emptiness is that apart from a categorical label, something constituting the self of a given entity, including humans, can never be located in time or space. This contrasts with the prevailing Western psychological view whereby the self is typically deemed to be an independent, definitive and autonomous entity.

There are numerous metaphysical standpoints from which emptiness can be understood, but a useful means of comprehending the phenomenon is to apply the Buddhist principle of interconnectedness. For example, the human body is composed of, and exists in dependence upon, water (e.g., from rain and the ocean), air (e.g., from the wind), animals, plants, nutrients, the heat of the sun, etc. Thus, it can be said that the human body (or any other phenomenon) is "full" of all things but "empty" of a self that exists either inherently or independently.

Another way to think of emptiness is to consider how phenomena appear in a dream. Dreamt phenomena invariably appear real to the dreamer and it would thus be incorrect to assert they are devoid of existence. But apart from mind-made projections that exist relative to each other, it is not possible to assign a quality of inherent or absolute existence to anything that manifests in a dream. According to some contemplative adepts, 
waking reality might be thought of as a shared dream that appears real and adheres to physical rules, but that ultimately does not exist outside the realm of collective consciousness.

However, although it is possible to come to a limited understanding of emptiness using examples such as the above, to be understood fully emptiness needs to be experienced directly. And given that most people are habituated to perceiving reality in dualistic (i.e., self-other) terms, specialist contemplative training is invariably required to induce such a direct experience.

\section{Benefits of Perceiving Emptiness}

According to Buddhist thought, wellbeing arises through a process of deconstructing the ego-self and resultant forms of attachment. More specifically, without a rigid belief in an inherently and independently existing "me" or "I," there is a reduced locus of self upon which conceptual and emotional baggage can accrue. Conversely, due to harboring implausible ontological and existential beliefs, individuals reify their sense of selfhood to the point that it weds them to narrow and egotistical cognitive behavioral response modes.

Empirical investigation of emptiness is still at an early stage (i.e., when compared with, for example, mindfulness) but emerging insights indicate a role for improving psychological and spiritual wellbeing. For example, in one of our own studies comparing a self-induced emptiness condition with mindfulness meditation in advanced Buddhist meditators, the former was more effective for improving mystical experiences, non-attachment, compassion, and mood (Van Gordon et al. 2019). Similarly, another study we conducted involving advanced Buddhist meditators found that selfinducing a state of emptiness was an important precursor to eliciting profound spiritual experiences, including insights into death (Van Gordon et al. 2018).

Some second-generation mindfulness-based interventions have started to employ Buddhist-derived wisdom practices, including emptiness techniques. Second-generation mindfulness-based interventions follow a more traditional approach to mindfulness by teaching it more in line with the aforementioned three-trainings principle (e.g., teaching mindfulness in conjunction with ethical, socio-empathic and wisdom-based meditative techniques). One such second-generation mindfulness approach integrating emptiness techniques is an intervention that we developed, called Meditation Awareness Training (MAT). MAT has been shown to improve a range of health, wellbeing, and human functioning outcomes in both clinical and non-clinical populations, including via randomized controlled trials, non-randomized controlled trials, and clinical case studies.

However, given the multi-component nature of interventions such as MAT, it is difficult to ascertain the specific effects of emptiness versus other aspects that are likely to be therapeutically active (e.g., mindfulness, compassion meditation, loving-kindness meditation, group engagement, psycho-education). Nevertheless, based on qualitative studies of MAT, participants who have elicited an experience of emptiness, albeit at an introductory level, report it to be meaningful and important for reducing ego-attachment, improving psychological flexibility and fostering psycho-spiritual wellbeing.

This is consistent with the growing body of research into non-attachment, which is positively correlated with a range of health and wellbeing indicators, such as non-reactivity and prosocial behavior, and which has also been shown to mediate the effects of mindfulness for improving chronic pain symptoms. Non-attachment links closely with emptiness because if an individual has low levels of attachment to objects, situations, people, or psychological processes (e.g., thoughts, feelings, memories), it implies that they have low levels of attachment to themselves. The reason for this, according to Buddhist thought, is that attachment to "other" necessitates the existence of, and belief in, a self, but such attachment processes start to fall apart as the individual begins to intuit that they are "empty" of an inherently existing self.

\section{Is Emptiness a Practice?}

Although in this paper we have referred to emptiness as a "practice," emptiness is more of a principle or truth. It is a fundamental characteristic of existence. It is the underlying fabric of which the universe is made, from which the universe was born, and to which the universe will return when it dies. Everything that exists is of the nature of emptiness. Our thoughts are of the substance of emptiness, the air we breathe is imbued with emptiness, and every step we take is a step within the domain of emptiness.

Because all things are empty, all things are equal. You are equal to us and we are equal to you. Although it might appear that you are there and we are here, in emptiness we are all inseparable. Indeed, in emptiness there is no here or there. No this or that. No good or bad. And no before or after. In fact, there is no emptiness because even emptiness is another empty concept. In emptiness, there is just simply being, but without getting caught up in being.

As we hope you are now beginning to understand, emptiness is something that needs to be intuited rather than studied or practiced per se. However, there are certain practices that can help to remove some of the psychological barriers that prevent the experience of emptiness from arising organically. Therefore, when we talk about practicing emptiness, we are really talking about practicing specific contemplative techniques that help to soften our normal way of perceiving, so that the right conditions for experiencing emptiness can arise. 


\section{How to Cultivate Emptiness}

In line with the three trainings principle, two important foundation practices for intuiting emptiness are (i) compassionate and ethical conduct, and (ii) meditative focus. Compassion helps prepare the mind for experiencing emptiness because it redirects focus away from the self and toward others. The less caught up in ourselves we are, the closer we get to understanding that the self does not exist independently or inherently. However, rather than relating to compassion as a "technique," it needs to be something that pervades our being and defines our outlook on life. Authentic compassion comes from the heart, and it should come from it all of the time.

Within this framework of compassionate and ethical living, regular daily sessions of focused meditation are also important. The mind tends to continuously churn out mental noise in the form of thoughts, feelings, concepts, worries, plans, ideas, and regrets. It's not possible to completely arrest mental activity, but focused and settled meditation can slow such processes down to the point that it becomes possible to start seeing through or beyond them.

In this manner, thoughts, feelings, and all other forms of psychological activity can be related to simply as observable phenomena that come and go. They should be perceived as being no more or less important than material objects or phenomena. We perceive material and psychological phenomena, we engage with them and enjoy them, but we let them go. All things manifest within, and are part of, the dance of impermanence; the continuous rising and falling of the multitude of transient phenomena that make up the present moment.

The very instant we experience something, that experience becomes history as it gives way to a new experience- a process that continues ad infinitum. Therefore, an effective way to cultivate meditative focus is to observe and accept everything that unfolds within the mind, but without holding on to it. Mindfulness should then be applied between meditation sessions as a means of maintaining continuity of contemplative awareness throughout the day.

Having developed a suitable level of proficiency in these foundation practices, the next step is to introduce a further stage at the end of a session of focused meditation. There are different techniques that can be applied for accessing emptiness in this respect, ranging from advanced forms of visualization to observing the entirety of experience as mind-made. However, perhaps the most accessible approach is to engage a more penetrative form of meditation once the foregoing phase of settled and focused meditation reaches a stage where each and every thought calmly glides through the mind without being held on to.

Penetrative meditation in this context involves directing meditative focus toward calmly searching for something that amounts to the self, me, or I. It's important to note that this isn't an intellectual form of analysis involving, for example, critical reasoning skills. It's much more subtle than that because the investigative search needs to unfold without interrupting meditative focus and serenity. The question of "exactly where is the self?" becomes the object of contemplative focus, but there should not be any expectations or urgency associated with trying to find the answer.

This intentional yet calmly executed search process should lead one to see that as part of the self, everything else exists trees, oceans, rivers, animals, food, parents, other people, stars, planets, the universe, etc. However, it should also lead to the conclusion that an independently and inherently existing self can never be found (i.e., because it does not exist). If the aforementioned foundation stages have been undertaken correctly, this process of meditative investigation can gradually trigger a form of contemplative intuition, whereby an experience of emptiness begins to arise of its own accord.

When the experience of emptiness starts to arise and one's view begins to expand exponentially, there can be a tendency for excitement or attachment (i.e., to former or ordinary ways of perceiving) to arise. But if the mind is suitably calm and focused to begin with, any such excitement or attachment can be subsumed within the experience of emptiness itself, thus preventing it from disturbing the continuity of insight and awareness.

As indicated by the following quotes collected as part of research we conducted with advanced Buddhist meditators, at the point of experiencing emptiness, all notions of space, time, self, and other are transcended:

Existence is happening. It's unfolding in front of you and you're watching it. But you're also part of it. You are it. You're dancing with it. Oh, it's so beautiful. All things and life forms are included in your view. And the sense of love and compassion is overwhelming. It comes naturally. You touch every mind and atom with your heart and mind.

It's a bit like returning home to the source. You bathe in emptiness. It's where everything begins and everything ends. You reconnect with the universe.

As much as possible, efforts should be made to maintain the experience of emptiness following meditation. Honed mindfulness skills, including practicing mindfulness of emptiness (Shonin et al. 2015), play an important role here. However, it's important not to force trying to summon or maintain an experience of emptiness. If you try to force it, it means you are holding on to me, mine, and I. You will never experience emptiness like this. Therefore, allow things to happen naturally and spontaneously. Fully enjoy and engage with whatever moment you find yourself in. But keep your mind supple, open, and free from attachment. By doing this, you 
weaken the habitual ways of dualistic and egoistic perceiving that inhibit contact with the truth of emptiness, which has always been right in front of you and all around you.

\section{Is Emptiness for Everyone?}

The idea that we don't inherently exist might be difficult for some people to accept. But this doesn't mean it isn't true. As noted previously, it also doesn't mean that things don't exist at all. Indeed, it's just as incorrect to associate emptiness with nothingness as it is to assume that phenomena exist absolutely (Van Gordon et al. 2017). Without emptiness, the multiplicity of phenomena known to humankind could simply not exist, as the inherently empty nature of the universe means that there is limitless space and potential in terms of the measure and type of phenomena that can manifest. Thus, it's worth reiterating that emptiness denotes "fullness" just as much as absence of inherent existence.

Since emptiness is a fundamental property of reality, it is correct that people are made aware of this scientific and philosophical truth. A major shift in paradigm across scientific disciplines and the general public will inevitably take time, but it's our view that emptiness is likely to gradually become a more mainstream idea in coming years. As scientific understanding of emptiness continues to grow, including its applications for helping human beings realize more of their potential for wellbeing and wisdom, public interest is likely to follow. A similar process unfolded with mindfulness which, just several decades ago, was far from being the popular and widely accepted notion it has become today.

However, although awareness and theoretical understanding of emptiness are likely to increase, the number of people who are genuinely able to intuit emptiness is likely to remain small. This is because embodying and fully experiencing emptiness goes hand-in-hand with overcoming egocentric predispositions, which requires serious dedication, years of focused daily contemplative practice, and the unremitting support of a suitably realized teacher. Nevertheless, it is certainly worthwhile guiding interested and suitably disposed individuals to an understanding - and perhaps also an introductory experience - of emptiness, which they can develop and refine as part of an ongoing routine of daily contemplative practice.

\section{A Cautionary Note}

As interest into emptiness increases, so will the number of books, courses, interventions, techniques, and teachers that seek to use or make reference to this ancient contemplative construct. Also, based on our experience, the nuanced nature of emptiness tends to entice intellectual debate, which can certainly be useful for advancing understanding. However, as has happened with mindfulness, the more mainstream emptiness becomes, paradoxically, the more distant most people are likely to become from encountering the truth that it represents. Even within the Buddhist monastic and teaching community, some so-called scholarly Buddhist teachers are sometimes all too eager to demonstrate what they deem to be knowledge of concepts such as emptiness. However, in general, such individuals end up propagating a superficial approach to contemplative practice, as well as advancing their ego rather than other people's understanding or wellbeing.

Therefore, if emptiness is something that interests you, please try to remember that ultimately, words, concepts, and intellect can never fully do justice to emptiness, as it can only be encountered through direct experience. Caution in this respect may go some way toward preventing emptiness from following in the path of McMindfulness and Kentucky Fried Compassion, or from being misconstrued and overconceptualized more generally.

\section{Compliance with Ethical Standards}

Conflict of Interest The authors declare that they have no conflicts of interest.

Open Access This article is licensed under a Creative Commons Attribution 4.0 International License, which permits use, sharing, adaptation, distribution and reproduction in any medium or format, as long as you give appropriate credit to the original author(s) and the source, provide a link to the Creative Commons licence, and indicate if changes were made. The images or other third party material in this article are included in the article's Creative Commons licence, unless indicated otherwise in a credit line to the material. If material is not included in the article's Creative Commons licence and your intended use is not permitted by statutory regulation or exceeds the permitted use, you will need to obtain permission directly from the copyright holder. To view a copy of this licence, visit http://creativecommons.org/licenses/by/4.0/.

\section{References}

Shonin, E., Van Gordon, W., Singh, N. N., \& Griffiths, M. D. (2015). Mindfulness of emptiness and the emptiness of mindfulness. In E. Shonin, W. Van Gordon, \& N. N. Singh (Eds.), Buddhist Foundations of Mindfulness (pp. 159-178). New York: Springer.

Van Gordon, W., Shonin, E., \& Griffiths, M. D. (2017). Buddhist emptiness theory: implications for psychology. Psychology of Religion and Spirituality, 9, 309-318.

Van Gordon, W., Shonin, E., Dunn, T., Sheffield, D., Garcia-Campayo, J., \& Griffiths, M. D. (2018). Meditation-induced near-death experiences: a three-year prospective study. Mindfulness, 9, 1794-1806.

Van Gordon, W., Shonin, E., Dunn, T., Sapthiang, S., Kotera, Y., GarciaCampayo, J., \& Sheffield, D. (2019). Exploring emptiness and its effects on non-attachment, mystical experiences, and psycho-spiritual wellbeing: a quantitative and qualitative study of advanced meditators. Explore: The Journal of Science and Healing, 15, 261-272.

Publisher's Note Springer Nature remains neutral with regard to jurisdictional claims in published maps and institutional affiliations. 